\title{
KLASYFIKACJA SEMANTYCZNA \\ ROSYJSKICH I POLSKICH NAZW MUZYKI ROZRYWKOWEJ
}

\author{
SEMANTIC CLASSIFICATION \\ OF NAMES OF POPULAR MUSIC GENRES IN RUSSIAN AND POLISH
}

\author{
RAFAE KOWALCZYK
}

\begin{abstract}
This paper presents a practical application of multifaceted research into the vocabulary of popular music in contemporary Russian and Polish. It contains explanatory notes in the first part and appendixes, i.e. mini Russian-Polish dictionaries, in the second part. Lexical entries are divided into six semantic groups with the following key concepts: jazz, rock, metal, house, techno and trance, which describe the music styles that appeal to popular tastes.
\end{abstract}

Rafał Kowalczyk, Uniwersytet Wrocławski, Wrocław - Polska.

\section{Część opisowa}

Proponowany uwadze czytelnika szkic ma dwa zamierzone cele: glottodydaktyczny i translatoryczny. Zamieszczone w nim aneksy (zob. część słownikowa) mogą służyć studentom i wykładowcom jako materiały poglądowe ${ }^{1}$ zarówno na zajęciach z nauki praktycznej języka rosyjskiego, jak i na zajęciach z przekładu, szczególnie funkcjonalnego. Tak więc z merytorycznego punktu widzenia mogą one być pomocne w rozwijaniu i utrwalaniu takich kompetencji, jak: językowa (gramatyczna i leksotaktyczna), tłumaczeniowa (recepcyjna i reprodukcyjna), terminologiczna i kulturowa².

${ }^{1}$ Zob. inne opracowane przeze mnie materiały poglądowe: R. K o w a l c z y k, Próbny rosyjsko-polski stownik teatralny, [w:] tegoż, Rosyjskie stownictwo teatralne w porównaniu $z$ polskim, "Slavica Wratislaviensia”, Wrocław: Wydawnictwo Uniwersytetu Wrocławskiego, 2005, nr CXXXVII, s. 125-134; tegoż, Nomina actionis $i$ nomina essendi w rosyjskim i polskim stownictwie teatralnym, "Rozprawy Komisji Językowej WTN”, Wrocław: Wydawnictwo WTN, 2006, nr XXXII, s. 149-158; tegoż, Ponadwyrazowe rosyjskie i polskie nazwy teatralne (skupienia z komponentami meamp - teatr), "Slavica Wratislaviensia”, Wrocław: Wydawnictwo Uniwersytetu Wrocławskiego, 2006, nr CXXXV, s. 133-144.

$2 \mathrm{O}$ wymienionych kompetencjach zob.: Tezaurus terminologii translatorycznej, red. nauk. J. Lukszyn, wyd. 2, Warszawa: Wydawnictwo Naukowe PWN, 1998, s. 155-157; F. S z u l c, Stownik dydaktyki języków obcych, wyd. 2, Warszawa: Wydawnictwo Naukowe PWN, 1997, s. 110-112. 
Wspomniane wyżej aneksy - będące aplikacyjnym zastosowaniem prowadzonych przeze mnie badań nad słownictwem muzyki rozrywkowej w rosyjskim i polskim areale kulturowym - zawierają ogółem 921 jednostek wyrazowych, w tym 478 rosyjskich i 443 polskie ${ }^{3}$. Układają się one w sześć grup tematycznych zawierających szczegółowe określenia muzyki: jazzowej, rockowej, metalowej i tanecznej ${ }^{4}$. Rzecz jasna, nie wyczerpują one w pełni analizowanej problematyki, są zaledwie próbą egzemplifikacji słownictwa show-biznesu muzycznego - zróżnicowanego nie tylko na płaszczyźnie znaczeń językowych, ale także na płaszczyźnie struktur formalnych.

Z genetycznego punktu widzenia wśród nominacji opisujących style muzyki rozrywkowej można wydzielić liczne nazwy obce. Wystarczy pobieżny ogląd materiału leksykograficznego, by stwierdzić, że zdecydowana większość jednostek tworzących poszczególne pola semantyczne pochodzi z języka angielskiego ${ }^{5}$ (хот-джаз, пауэр-рок, блэк-метал( $)$; bassline house, hard techno, vocal trance). Można je odnotować w wielu językach, a to oznacza, że mają status internacjonalizmów. Innymi słowy, nazewnictwo muzyki popularnej, a na pewno jej podstawowy zasób, ma charakter międzynarodowy ${ }^{6}$.

$\mathrm{Z}$ formalnogramatycznego punktu widzenia nazwy: джаз, рок, метал $(\Omega)$, хаус, техно, mранс; jazz, rock, metal, house, techno, trance wykazują zdolność

${ }^{3}$ Materiał faktograficzny wyekscerpowałem z wielu źródeł drukowanych (wykaz najważniejszych z nich umieszczony jest po części słownikowej); korzystałem także z portali poświęconych muzyce rozrywkowej.

4 Por. słownictwo muzyczne opracowane przez R. M a r c i n k i e w i c z a, [w:] Podręczny idiomatykon polsko-rosyjski, pod red. W. Chlebdy, z. 3, Opole: Wydawnictwo Uniwersytetu Opolskiego, 2008, s. 149-167.

${ }^{5} \mathrm{O}$ wpływach angielskich w ruszczyźnie i polszczyźnie zob. m.in.: В.M. А р и с т о в а, Английские слова в русском языке. Учебное пособие, Калининград: Изд-во Калининг. ун-та, 1985; М.А. Б р е й т е р, Англицизмы в русском языке: история и перспективы. Пособие для иностр. студентов-русистов, Москва: Изд-во АО „Диалог-МГУ”, 1997; Х. В а ль т е р, О. В о в к, А. 3 у мп, Х. К о н уп к о в а, А. Ку ль п а, В. П о р ос, Словарь. Заимствования в русском субстандарте. Англицизмы, Москва: „Ити Технологии", 2004; Л.П. К р ы с и н, Заимствование иноязычной лексики русским языком ХХ века, [w:] tegoż, Русское слово, свое и чужое. Исследования по современному русскому языку и социолингвистике, Москва: „Языки славянской культуры”, 2004, s. 72-226; M. W ó j t o w і с z, Характеристика заимствованных из англииского языка имен существительных в русском языке, Poznań: Wydawnictwo Naukowe UAM, 1984; K. L u c i ń s k i, Anglicyzmy w języku polskim i rosyjskim, Kielce: Wydawnictwo AŚ im. J. Kochanowskiego, 2000; E. M a ń c z a k - W o h 1 f e l d, Angielsko-polskie kontakty językowe, Kraków: Wydawnictwo Uniwersytetu Jagiellońskiego, 2006.

${ }^{6}$ Szerzej o przejawach internacjonalizacji w słownictwie muzycznym zob. G. D ą b k o w s k i, Europejska terminologia muzyczna, Kielce: Wydawnictwo WSP im. J. Kochanowskiego, 1997. 
do łączenia się w grupy wyrazowe. Są to głównie skupienia atrybutywne, tj. frazy nominalne, w skład których wchodzą: przymiotnik i rzeczownik - szyk dla analityzmów rosyjskich (индустриальный метал(^), психоделический рок, симфонический транс, чикагский джаз), rzeczownik i przymiotnik - szyk dla analityzmów polskich (house minimalistyczny, jazz modalny, rock instrumentalny, techno eksperymentalne). Ze względu na to, że określają one pojęcia specjalistyczne, zasięg ich użycia ogranicza się do działalności muzycznej (słownictwo: kompozytorów, wykonawców, didżejów, turntablistów, menedżerów, producentów, a także fanów, muzykologów, krytyków), można je więc traktować jako jednostki leksyki specjalnej.

$\mathrm{Z}$ moich obserwacji wynika, że te same pojęcia muzyczne mogą określać kalki semantyczne i strukturalne (por.: арена-рок - стадионный рок; мелодик-транс - мелодическии транс; progressive house - house progresywny; southern rock - rock potudniowy). Z przytoczonego faktu wynika ważna cecha wszystkich poniższych zbiorów wyrazowych, a zarazem obydwu zasobów nazewniczych, mianowicie zjawisko synonimii leksykalnej. Szeregi synonimiczne mogą liczyć od dwóch do pięciu nominacji (кислотный транс - эйсид-транс; белый метал $(\Omega)$ - светлый метал $(\Omega)$ - уайт-метал $(\Omega)$ - христианский метал( () ; alt rock - alternative rock - rock alternatywny; electronic jazz - e-jazz - jazztronica - jazz elektroniczny - nu jazz). Znamienne są także inne cechy. W zebranym materiale empirycznym można wyodrębnić nazwy, między którymi zachodzą relacje konwersji (por.: авангардный джаз - традиционный джаз; софт-транс - хард-транс; христианский метал( $)$ - языческий метал( () ; black metal - white metal; hard rock - soft rock; jazz archaiczny - jazz nowoczesny), oraz nazwy ilustrujące zjawisko homonimii (por.: pok I. 'los, fatum', II. 'styl muz.'; тяжелый метал - metal ciężki I. 'termin w chemii i fizyce', II. 'styl muz.'; trans I. 'stan psychiczny', II. 'styl muz.').

W licznych źródłach rosyjskich i polskich, w tym internetowych, poświęconych muzyce popularnej można zaobserwować odmienną pisownię wielu obcych nazw muzycznych. Wobec tego w poniższych słowniczkach przytaczam warianty graficzne (nр.: этно-рок, этнорок; techno house, techno-house) oraz fonetyczne (nр.: смус-джаз, смут-джаз; хэви-мэтл; rokendrol). Wnikliwa lektura rosyjskich muzycznych kompendiów słownikowo-encyklopedycznych pozwala mi stwierdzić, że w przypadku obcych nazw muzyki rozrywkowej ich autorzy często stosują tę samą regułę ortograficzną, tj. zapis poprzez dywiz, choć inna może być pisownia w języku zapożyczenia, głównie angielskim (por.: punk rock - naнk-poк; west coast jazz - becm-коуст-джаз).

W słowniczkach stosuję dwa znaki: $\rightarrow$ (odsyła do innego hasła), // (oznacza współistnienie form obocznych). 


\title{
Część słownikowa
}

\author{
A neks n r 1 \\ Rosyjsko-polski słowniczek nazw muzyki jazzowej
}

авангардный джаз jazz awangardowy, avant-garde jazz

архаический джаз jazz archaiczny, archaic jazz

афро-кубинский джаз jazz afrokubański, afro-cuban jazz

барок-джаз baroque jazz

биг-бэнд-джаз big band jazz

вест-коуст-джаз // Вест-Коуст-джаз

$\rightarrow$ джаз Западного побережья

гарлемский джаз Harlem jazz

горячий джаз $\rightarrow$ хот-джаз

джаз-блюз jazz blues

джаз Восточного побережья jazz Wschodniego Wybrzeża, east coast jazz, East Coast jazz

джаз Западного побережья jazz Zachodniego Wybrzeża, west coast jazz, West Coast jazz

джаз-авангард $\rightarrow$ авангардный джаз

джаз-мануш jazz manouche

джаз-метал(л) jazz metal

джаз-поп jazz pop

джаз-рок jazz rock

джаз-рэп jazz rap

джазтроника jazztronica

джаз-фанк jazz funk

джаз-фьюжн jazz fusion

джаз-хаус jazz house

диско-джаз disco jazz, dance jazz

душевный джаз $\rightarrow$ соул-джаз

ист-коуст-джаз // Ист-Коуст-джаз

$\rightarrow$ джаз Восточного побережья

калифорнийский джаз $\rightarrow$ джаз Западного побережья

камерный джаз jazz kameralny, chamber jazz

Канзас-Сити-джаз Kansas City jazz кислотный джаз $\rightarrow$ эйсид-джаз классик-джаз classical jazz классический джаз jazz klasyczny коммерческий джаз jazz komercyjny континентальный джаз jazz kontynentalny, continental jazz креольский джаз Creole jazz кроссовер-джаз crossover jazz кубинский джаз cuban jazz

кул-джаз cool jazz

ладовый джаз $\rightarrow$ модальный джаз

латин-джаз latin jazz

латиноамериканский джаз jazz latynoamerykański

лофт-джаз loft jazz

мини-джаз mini-jazz

модальный джаз jazz modalny, modal jazz

модерн-джаз modern jazz

нью-джаз nu-jazz, nu jazz

нью-йоркский джаз jazz nowojorski,

New York jazz

нью-орлеанский джаз jazz nowoorleański, New Orlean jazz

оркестровый джаз jazz orkiestralny, orchestral jazz

панк-джаз punk jazz

приглаженный джаз $\rightarrow$ смут-джаз

прогрессив-джаз progressive jazz

прогрессивный джаз jazz progresywny

прото-джаз // протоджаз proto-jazz, pro- tojazz

прохладный джаз $\rightarrow$ кул-джаз

свит-джаз // суит-джаз sweet jazz

свободный джаз $\rightarrow$ фри-джаз

симфо-джаз // симфоджаз $\rightarrow$ симфонический джаз

симфоник-джаз symphonic jazz

симфонический джаз jazz symfoniczny

ска-джаз ska jazz

смус-джаз // смут-джаз // смуф-джаз smooth jazz

современный джаз jazz nowoczesny

софт-джаз soft jazz

соул-джаз soul jazz

стрейт-джаз $\rightarrow$ чикагский джаз

традиционный джаз jazz tradycyjny, traditional jazz

трэд-джаз trad jazz 
трэш-джаз thrash jazz

уэст-коуст-джаз // Уэст-Коус-джаз

$\rightarrow$ джаз Западного побережья

фолк-джаз folk jazz

фри-джаз free jazz

хип-хоп-джаз hip hop jazz, hip-hop jazz,

jazz hop

хот-джаз hot jazz

цыганский джаз gypsy jazz чикагский джаз jazz chicagowski, Chicago jazz

эйсид-джаз // эсид-джаз acid jazz

электронный джаз jazz elektroniczny, electronic jazz

электро-джаз electro-jazz, e-jazz

этник-джаз // этно-джаз // этноджаз

etno-jazz, etnojazz

A neks n r 2

Rosyjsko-polski słowniczek nazw muzyki rockowej

авангардный рок rock awangardowy, avant-garde rock

альт-рок // альтрок alt rock

альтернативный poк rock

alternatywny, alternative rock

андеграунд-рок underground rock

андеграундный рок rock undergrounddowy

арена-рок arena rock, stadium rock

арт-рок art rock

aфpo-poк arfo rock

бабблгам-рок buble gum rock

байкер-рок biker rock, grebo rock

бард-рок w Rosji: nazwa stylu lat 70. $i$ 80.

$X X$ w., powstałego w wyniku symbiozy poezji bardów: A. Galicza, B. Okudżawy, W. Wysockiego i rocka

барок-рок baroque rock

блюз-рок blues rock

брасс-рок brass rock

буги-рок boogi rock

гаражный рок rock garażowy, garage rock

гитарный рок rock gitarowy, guitaroriented rock

гламурный рок $\rightarrow$ глэм-рок

глиттер-рок glitter rock

глэм-рок glam rock

готик-рок gothic rock

готический рок rock gotycki

гранж-рок grunge rock

евро-рок euro-rock

индастриал-рок industrial rock

инди-рок indie rock

индустриальный poк rock industrialny инструментальный рок rock instrumentalny, instrumental rock

кантри-рок country rock

кислотный рок $\rightarrow$ эйсид-рок

классик-рок classic rock

классический рок rock klasyczny

кок-рок cock rock

колледж-рок college rock

комеди-рок comedy rock

концептуальный рок conceptualised rock

космик-рок $\rightarrow$ спейс-рок

космический рок rock kosmiczny

краут-рок kraut rock, krautrock

латин-рок latin rock

мат-рок math rock

медиевал-рок medieval rock

минималистский рок rock minimalisty-

czny

мод-рок mod rock

мок-рок mock rock

мягкий рок rock lekki

независимый рок rock niezależny

нео-классик-рок // неоклассик-рок

neoclassical rock, neo classical rock

неоклассический рок rock neoklasyczny

нео-прогрессив-рок // неопрогрессив-

рок neoprogressive rock, neo progressive rock

неопрогрессивный рок rock neoprogresywny

нео-рокабилли // неорокабилли neorockabilly, neo-rockabilli, neo rockabilly

нойз-рок noise rock

нью-рок nu-rock, nu rock

паб-рок pub rock 
панк-рок punk rock

пауэр-рок power rock

подпольный рок $\rightarrow$ андеграундный рок

помп-рок роmp rock

помпезный рок $\rightarrow$ помп-рок

поп-рок рор rock

пост-рок // построк post-rock, postrock

прог-рок // прогрок prog rock

прогрессив-рок progressive rock

прогрессивный рок rock progresywny

психоделик-рок psychedelic rock

психоделический рок rock psychodeli-

czny, rock psychedeliczny

рага-рок raga rock

ретро-рок retro rock

рокабилли rockabilly

рок-авангард $\rightarrow$ авангардный рок

рок для взрослых $\rightarrow$ эдалт-ориентидрок

рок Западного побережья rock Zachodniego Wybrzeża, West Coast rock

рок-н-ролл // рок'н'ролл rock and roll, rock'n'roll, rokendrol

рок-н-рэп // рок'н'рэп rock and rap, rock'n'rap

рок-подполье $\rightarrow$ подпольный рок

рок-ривайвл rock revival, renesans rocka рок-стеди // рокстеди rocksteady

рэп-рок $\rightarrow$ рок-н-рэп

сайкеделик-рок $\rightarrow$ психоделик-рок

саутерн-рок southern rock

свамп-рок swamp rock

серф-рок surf rock

симфоник-рок symphonic rock

симфонический рок rock symfoniczny

симфо-рок // симфорок symphorock

синт-рок // синти-рок synth rock, synthi rock скузз-рок scuzz rock слиз-рок sleaze rock соул-рок soul rock софт-рок soft rock, piano rock спейс-рок // спэйс-рок space rock срамной рок $w$ Rosji: nazwa stylu, w którym głównym środkiem oddziaływania jest tekst nasyco-ny obscenami, muzyka ma mniejsze znaczenie

стадионный рок rock stadionowy стонер-рок // стоунер-рок stoner rock твердый рок $\rightarrow$ тяжелый рок техно-рок techno-rock, techno rock триллер-рок $\rightarrow$ хоррор-рок трип-рок trip rock трэш-рок thrash rock ту-тоун-рок two-tone rock тяжелый рок rock ciężki уэст-коуст-рок $\rightarrow$ рок Западного побережья

фанк-рок funk rock

фолк-рок folk rock

фрат-рок frat rock

хард-рок hard rock

хард-рок-фьюжн hard rock fusion

хоррор-рок horror rock

христианский рок rock chrześcijański, rock natchniony, christian rock

хэви-рок // хеви-рок heavy rock

чикано-рок chicano rock, rock latynoski шок-рок shock rock

южный рок rock południowy

эдалт-ориентид-рок adult-oriented rock электронный рок rock elektroniczny, electronic rock

электро-рок electro-rock

эйсид-рок // эсид-рок acid rock

этно-рок // этнорок etno-rock, etnorock

A neks n r 3

Rosyjsko-polski słowniczek nazw muzyki metalowej

авангардный метал(л) metal awangardowy, avant-garde metal

альтернативный метал(л) metal alternatywny, alternative metal альт-метал(л) // альтметал(л) alt metal анблэк-метал(л) unblack metal андеграунд-метал(л) underground metal 
андеграундный метал(л) metal undergroundowy

атмосферик-блэк-метал(л) atmospheric black metal

атмосферный блэк-метал(л) black metal nastrojowy

белый метал(л) $\rightarrow$ уайт-метал(л)

блэк-дум-метал(л) black doom metal блэк-дэт-метал(л) black death metal блэк-метал(л) black metal, blek metal брутал-дэт-метал(л) brutal death metal брутальный дэт-метал(л) death metal brutalny

викинг-метал(л) viking metal

викингский метал(л) $\rightarrow$ викинг-метал(л)

волосатый метал(л) $\rightarrow$ хэир-метал(л)

глэм-метал(л) glam metal

готик-дум-метал(л) gothic doom metal готик-метал(л) gothic metal, goth metal готический метал(л) metal gotycki грув-метал(л) groove metal дарк-метал(л) dark metal депрессив-блэк-метал(л) depressive black metal

деперессивно-суицидальный блэк-метал(л) black metal depresyjno-samobójczy, depressive suicidal black metal депрессивный блэк-метал(л) black metal depresyjny

джаз-рок-метал(л) jazz rock metal

дроун-дум-метал(л) drone doom metal дроун-метал(л) drone metal

дум-метал(л) doom metal

дэз-метал(л) // дэс-метал(л) // дэт-метал(л) // дэф-метал(л) death metal дэт-дум-метал(л) death doom metal дэт-трэш-метал(л) death thrash metal жизнеутверждающий метал(л) $\rightarrow$ уайт-метал(л)

индастриал-блэк-метал(л) industrial black metal

индастриал-метал(л) industrial metal инди-метал(л) indie metal

индустриальный блэк-метал(л) black metal industrialny индустриальный метал(л) metal industrialny

классический хэви-метал(л) classic heavy metal

лав-метал(л) love metal

медиевал-метал(л) medieval metal

метал(л)кор metalcore

мелодик-блэк-метал(л) melodic black metal

мелодик-дэт-метал(л) melodic death metal

мелодический блэк-метал(л) black metal melodyczny

мелодический дэт-метал(л) death metal melodyczny

метал(л)-авангард $\rightarrow$ авангардный метал(л)

метал(л)орок // метал(л)о-рок metalorock, metal rock

нео-классик-метал(л) // неоклассикметал(л) neoclassical metal, neo classical metal

неоклассический метал(л) metal neoklasyczny

новая волна британского хэви-метал(л)а nowa fala brytyjskiego heavy metalu, new wave of British heavy metal

ну-метал(л) // ню-метал(л) // нью-метал(л) nu-metal, nu metal

оккультный метал(л) occult metal оркестрал-метал(л) orchestral metal паган-метал(л) // пейган-метал(л) // пэган-метал(л) pagan metal паган-блэк-метал(л) pagan black metal пауэр-метал(л) power metal поп-метал(л) pop metal похоронный дум-метал(л) $\rightarrow$ фьюнерал-дум-метал(л)

прог-метал(л) // прогметал(л) prog metal прогрессив-дэт-метал(л) progressive death metal

прогрессив-метал(л) progressive metal прогрессивный дэт-метал(л) death metal progresywny

прогрессивный метал(л) metal progresywny 
реггей-метал(л) // рэггей-метал(л) // регги-метал(л) // рэгги-метал(л) reggae metal

ретро-метал(л) retro metal

рэп-метал(л) rap metal

сатаник-метал(л) satanic metal

сатанинский метал(л) metal sataniczny, metal diaboliczny

саутерн-метал(л) southern metal

светлый метал(л) $\rightarrow$ уайт-метал(л)

симфо-блэк-метал(л) $\rightarrow$ симфонический блэк-метал(л)

симфо-готик-метал(л) $\rightarrow$ симфонический готик-метал(л)

симфо-метал(л) / / симфометал(л)

$\rightarrow$ симфонический метал(л)

симфо-пауэр-метал(л) $\rightarrow$ симфонический пауэр-метал(л)

симфоник-блэк-метал(л) symphonic

black metal

симфоник-готик-метал(л) symphonic gothic metal

симфоник-метал(л) symphonic metal, opera metal

симфоник-пауэр-метал(л) symphonic power metal

симфонический блэк-метал(л) black metal symfoniczny

симфонический готик-метал(л) gothic metal symfoniczny

симфонический метал(л) metal symfoniczny

симфонический пауэр-метал(л) power metal symfoniczny

сладж-дум-метал(л) sludge doom metal

славянский фолк-метал(л) slavonic folk metal

сладж-метал(л) sludge metal

софт-метал(л) soft metal спид-метал(л) speed metal спид-пауэр-метал(л) speed power metal спид-треш-метал(л) speed thrash metal стоунер-дум-метал(л) stoner doom metal стоунер-метал(л) stoner metal техничный дэт-метал(л) death metal techniczny, technical death metal техно-дэт-метал(л) techno death metal техно-метал(л) techno metal традиционный хэви-метал(л) heavy me-

tal tradycyjny, traditionnal heavy metal трэш-метал(л) thrash metal

тяжелый метал(л) metal ciężki

уайт-метал(л) white metal

фанк-метал(л) funk metal

фолк-метал(л) folk metal

фьюнерал-дум-метал(л) funeral doom metal

хардкор-метал(л) hard core metal

хоррор-метал(л) horror metal, theatrical metal

христианский блэк-метал(л) black metal chrześcijański, christian black metal христианский метал(л) metal chrześci- jański, christian metal хэви-дум-метал(л) heavy doom metal хэви-метал(л) // хеви-метал(л) // хэвиметл // хэви-мэтл // хэви-мэтал heavy metal, hejwi metal

хэир-метал(л) hair metal, pudel metal чёрный метал(л) metal czarny электронный метал(л) electronic metal эмбиент-блэк-метал(л) ambient black metal

языческий блэк-метал(л) black metal pogański

языческий метал(л) metal pogański экстремальный метал(л) metal ekstremalny

A neks n r 4

Rosyjsko-polski słowniczek nazw muzyki house

балеарик-хаус balearic house бангра-хаус // бхангра-хаус bhangra house бейслайн-хаус bassline house брейк-хаус break house гаридж-хаус garage house гетто-хаус ghetto house глубокий хаус house głęboki гэраж-хаус $\rightarrow$ гаридж-хаус дарк-хаус dark house дип-хаус deep house 
диско-хаус disco house

дрим-хаус dream house, dreaming house итало-хаус italo house

кислотный хаус $\rightarrow$ эйсид-хаус

латин-хаус latin house

микро-хаус // микрохаус microhouse

минималистский хаус house minimali-

styczny

минимал-хаус minimal house

мрачный хаус house mroczny

прогрессивный хаус house progresywny

прогрессив-хаус progressive house

рага-хаус ragga house

ска-хаус ska house

сонный хаус house senny

ступид-хаус stupid house тек-xayc tech house

техно-хаус techno-house, techno house трайбл-хаус tribal house

тяжелый хаус house ciężki

фанки-хаус funky house

филтер-хаус filter house

френч-хаус french house

Чикаго-хаус // чикаго-хаус Chicago house чикагский хаус $\rightarrow$ Чикаго-хаус

фиджет-хаус fidget house

хард-хаус hard house

хаус-рэп house rap

хип-хаус hip house

хэппи-хаус //хепии-хаус happy house

эйсид-хаус // эсид-хаус acid house

эмбиент-хаус ambient house

A neks n r 5

Rosyjsko-polski słowniczek nazw muzyki techno

даб-техно dub techno

данс-техно // дэнс-техно dance techno

Детройт-техно // детройт-техно Detroit techno

детройтское техно $\rightarrow$ Детройт-техно

диско-техно disco techno

евро-техно euro-techno

интеллиджент-техно intelligent techno

кислотное техно $\rightarrow$ эйсид-техно

минималистское техно techno minima-

listyczne

минимал-техно minimal techno

пампин-техно pumpin' techno

софт-техно soft techno техно-бангра // техно-бхангра techno-bhangra, techno bhangra

техно-фанк techno-funk, techno funk

тяжелое техно techno ciężkie

умное техно $\rightarrow$ интеллиджент-техно

хардкор-техно hardcore techno

хард-техно hard techno

эйсид-техно // эсид-техно acid techno

экспериментал-техно experimental techno

экспериментальное техно techno ekspe-

rymentalne

электро-техно electro-techno

эмбиент-техно ambient techno

этно-техно // этнотехно etno-techno, etnotechno

A neks n 6

Rosyjsko-polski słowniczek nazw muzyki trance

аплифтинг-транс uplifting trance вокал-транс vocal trance

вокальный транс $\rightarrow$ вокал-транс

гибрид-транс hybrid trance

гоа-транс goa trance

дарк-транс dark trance

дрим-транс dream trance

евро-транс euro-trance

кислотный транс $\rightarrow$ эйсид-транс мелодик-транс melodic trance мелодический транс trans melodyczny мрачный транс trans mroczny нео-транс // неотранс neo-trance, neotrance

прогрессивный транс trans progresywny прогрессив-псай-транс progressive psytrance

прогрессив-транс progressive trance 


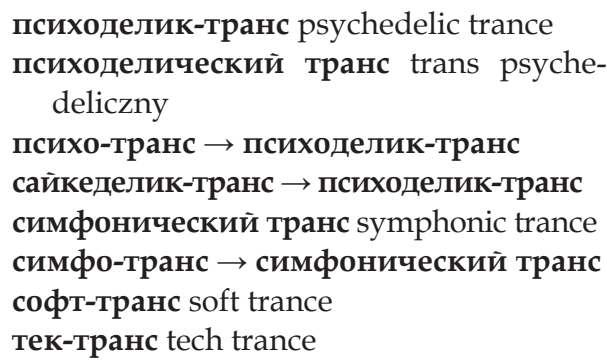

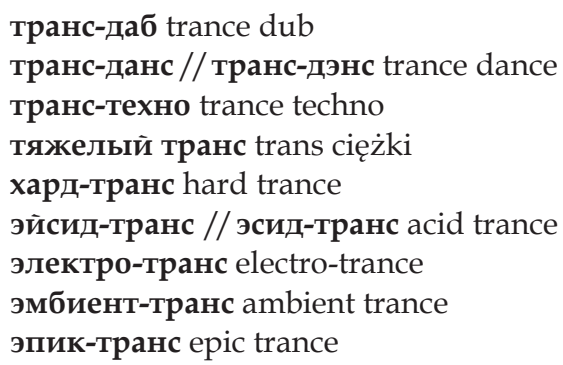

Wykaz najważniejszych źródeł wykorzystanych przy ekscerpcji nazw stylów muzyki rozrywkowej

All Music Guide to Rock. The Definitive Guide to Rock, Pop, and Soul, 3'rd ed., ed. by V. Bogdanov, Ch. Woodstra, S.T. Erlewine, San Francisco: „Backbeat Books”, „All Media Guide", 2002.

Bartas P., Rock \& Metal Book. Encyklopedie hard rocku a heavy metalu, Praha: „Volvox Globator", 2005.

Berendt J.E., Od raga do rocka. Wszystko o jazzie, wyd. nowe, tł. S. Haraschin, I. i W. Pankowie, Warszawa: PWM, 1979.

Bukszpan D., Heavy metal. Encÿklöpedie, předml. R.J. Dio, přeložil R. Lipčik, Praha: „BB/art”, 2004.

Crampton L., Rees D., Rock \& Pop. Zespoty, artyści, przeboje, koncerty, red. M. Grabowski, tł. P. Braiter, Warszawa: „Hachette Livre Polska”, 2004.

Encyklopedia muzyki popularnej. Heavy Metal, tł. K. Sawala, P. Żebrowski, uzupeł. i red. merytoryczna P. Kosiński, T. Słoń, A. Wójcik, Poznań: „Atena”; Kraków: „Rock-Serwis", 1994.

Encyklopedia muzyki popularnej. Rap, dance, techno, tł. T. Szczegóła, J. Weckwerth, uzupeł. i red. merytoryczna D. Świątkowska, S. Pękala, H. Wrona, Warszawa: „Atena”, 1997.

Gall Z., Pojmovnik popularne glazbe, (Biblioteka „Mali mrav”, knj. 2), Koprivnica: „Šareni dućan", 2001.

Gligo N., Pojmovni vodič kroz glazbu 20. stoljeća s uputama za pravilnu uporabu pojmova, Zagreb: Muzički informativni centar KDZ, Matica hrvatska, 1996.

Gloger R., Skrzydlewski W., Ilustrowany leksykon muzyki popularnej, Poznań: „Kurpisz”, 2002.

Gnioński L., Skaradziński J., Encyklopedia polskiego rocka, wyd. 3, Poznań: „In Rock”, 2001.

Kajtoch W., Jezzykowe obrazy świata i człowieka w prasie młodzieżowej i alternatywnej, t. I-II, Kraków: Wydawnictwo Uniwersytetu Jagiellońskiego, 2008.

McIver J., Nu-metal: encyklopedia, tł. L. Haliński, Poznań: „In Rock”, 2002.

Niedziela J., Historia jazzu. 100 wykładów, Katowice: „infoMAX®”, 2009.

Panek W., Encyklopedia muzyki rozrywkowej, Warszawa: „Świat Książki”, 2000.

Podręczny idiomatykon polsko-rosyjski, pod red. W. Chlebdy, z. 3, Opole: Wydawnictwo Uniwersytetu Opolskiego, 2008. 
Siron J., Dictionnaire des mots de la musique, 3e éd. (rev., corr. et augm.), Paris: „Outre Mesure", 2006.

Quarantotto C., Dizionario della musica pop \& rock, Roma: „Tascabili Economici Newton”, 1994.

Waschko R., Przewodnik ISKIER: muzyka jazzowa i rozrywkowa, Warszawa: „Iskry”, 1970.

Wicke P. und W. \& K.-E. Ziegenrücker, Handbuch der populären Musik. Geschichte. Stile. Praxis. Industrie, erwait. neuausg., Mainz: „Schott”, 2007.

Wolański A., Stownik terminów muzyki rozrywkowej, Warszawa: Wydawnictwo Naukowe PWN, 2000.

Wolański R., Pop, rock, jazz, folk. Leksykon polskiej muzyki rozrywkowej, t. I-III. Warszawa: Agencja Artystyczna MTJ, 2003.

Азаров А.А., Русско-английский энииклопедический словарь искусств и художественных ремесел. The Russian-English Encyclopedic Dictionary of the Arts and Artistic Crafts, т. 1-2, Москва: „Флинта”, „Наука”, 2005.

Альтернативная культура. Энциклопедия, сост. Д. Десятерик, Екатеринбург: „Ультра. Культура", 2005.

Бондаренко В.В., Дроздов Ю.В., Энщиклопедия популярной музыки, Минск: „Экономпресс", 2006.

Брюстер Б., Броутон Ф., История диджеељ, пер. с англ. М. Леоновича, Екатеринбург: „Ультра. Культура", 2007.

Верменич Ю.Т., Джаз. История. Стили. Мастера, СПб.: „Лань”, „Планета Музыки”, 2009.

Горохов А., Музпросвет, Москва: „Флюид”, 2010.

Грачев И.Ю., Энциклопедия Power / Speed Metal, Королев: „Нота-Р”, 2004.

Энииклопедия Gothic / Doom Metal, Королев: „Нота-P”, 2006.

Диджей: Играющий b темноте, сост. DJ Шевцов, DJ Miller, DJ Шмель, DJ Карпекин, Москва: „АСТ”; СПб.: „Астрель-СПб”, 2010.

Козлов А., Рок глазами джазмена, Москва: „Городец”, 2008.

Козлов В.В., Реальная культура: от Альтернативы до Эмо, СПб.: „Амфора”, 2009.

Королев О.К., Краткий энииклопедический словарь джаза, рок- и поп-музыки. Термины и понятия, Москва: „Музыка”, 2006.

Костюк Е.Б., Популярные музыкальные направления и жанры ХХ века: джаз, мюзикл, рокмузыка, рок-опера. Учеб. пособие, СПб.: Изд-во СПбГУП, 2008.

Крэмптон Л., Риз В., Rock \& Рор. Энциклопедия. Рок- и поп-музыка год за годом, пер. с англ. У.В. Сапциной, Н.С. Гусевой, консультант В.И. Ильинский, Москва: „Росмэн-Издат”, 2004.

Лысова Ж.А., Англо-русский и русско-английский музыкальный словарь, СПб.: „Лань”, 1999.

Рок-эницилопедия, автор и сост. С. Кастальский, Москва: „Ровесник”, 1997.

Словарь музыкальных терминов, сост. Е.А. Яных, Москва: „АСТ”; Донецк: „Агата”; Владимир: „ВКТ”, 2009.

Современная энииклопедия Аванта. Музыка наших дней, вед. ред. Д. Володихин, Москва: „Аванта+”, 2002. 
Троицкий А., Poplexтм, СПб.: „Амфора”, 2009.

Фейертаг В.Б., Джаз. Энииклопедический справочник, 2-е изд., перераб. и доп., СПб.: „Скифия", 2008.

Цалер И.В., Популярная музыка ХХ века: джаз, блюз, рок, поп, кантри, фолк, электроника, соул, Москва: „Мир энциклопедий Аванта+”, „Астрель”, 2010.

Энииклопедия русского рока, ред.: А. Трофимов, С. Бушуева, фотогр. И. Колбасов, Москва: „A.T. Publishing”, 2008. 